\title{
Metabolic syndrome induced by anticancer treatment in childhood cancer survivors
}

\author{
Hee Won Chueh, MD, PhD \\ Jae Ho Yoo, MD,PhD
}

Department of Pediatrics, Dong-A University Hospital, Dong-A University College of Medicine, Busan, Korea
Received: 29 May, 2017

Accepted: 11 June, 2017

Address for correspondence:

Jae Ho Yoo, MD, PhD

Department of Pediatrics, Dong-A University Hospital, Dong-A University College of Medicine, 26 Daesingongwon-ro, Seo-gu, Busan 49201, Korea

Tel: $+82-51-240-5124$

Fax: $+82-51-242-2765$

E-mail: pedendo@dau.ac.kr

https://orcid.org/0000-0003-3065944X
The number of childhood cancer survivors is increasing as survival rates improve. However, complications after treatment have not received much attention, particularly metabolic syndrome. Metabolic syndrome comprises central obesity, dyslipidemia, hypertension, and insulin resistance, and cancer survivors have higher risks of cardiovascular events compared with the general population. The mechanism by which cancer treatment induces metabolic syndrome is unclear. However, its pathophysiology can be categorized based on the cancer treatment type administered. Brain surgery or radiotherapy may induce metabolic syndrome by damaging the hypothalamic-pituitary axis, which may induce pituitary hormone deficiencies. Local therapy administered to particular endocrine organs directly damages the organs and causes hormone deficiencies, which induce obesity and dyslipidemia leading to metabolic syndrome. Chemotherapeutic agents interfere with cell generation and growth, damage the vascular endothelial cells, and increase the cardiovascular risk. Moreover, chemotherapeutic agents induce oxidative stress, which also induces metabolic syndrome. Physical inactivity caused by cancer treatment or the cancer itself, dietary restrictions, and the frequent use of antibiotics may also be risk factors for metabolic syndrome. Since childhood cancer survivors with metabolic syndrome have higher risks of cardiovascular events at an earlier age, early interventions should be considered. The optimal timing of interventions and drug use has not been established, but lifestyle modifications and exercise interventions that begin during cancer treatment might be beneficial and tailored education and interventions that account for individual patients' circumstances are needed. This review evaluates the recent literature that describes metabolic syndrome in cancer survivors, with a focus on its pathophysiology.

Keywords: Neoplasms, Antineoplastic protocols, Survivors, Metabolic syndrome X, Life style

\section{Introduction}

The incidence of childhood cancer in South Korea has gradually increased, because detection and diagnostic technologies have improved ${ }^{1)}$. The childhood cancer patient survival rate has also improved to over $78 \%{ }^{1}$, because of improvements in the treatment modalities and supportive care. Hence, there are more adult childhood cancer survivors who are experiencing the delayed effects of cancer treatment and whose quality of life is compromised. Among the complications associated with cancer treatment, metabolic syndrome is an important delayed manifestation that is strongly associated with the quality of life. Metabolic syndrome comprises a cluster of cardiovascular risk factors, namely, central obesity, insulin resistance, dyslipidemia, and hypertension ${ }^{2}$. The increased risk of metabolic syndrome among childhood cancer survivors was first noted in $1996^{3)}$, and increased rates of metabolic syndrome and cardiovascular risk factors among cancer survivors have been reported subsequently ${ }^{2,4,5)}$. In 
South Korea, investigations into metabolic syndrome among childhood cancer survivors have been limited, because they have comprised single center studies or involved small numbers of patients ${ }^{6-9)}$. This review evaluates the recent literature that describes metabolic syndrome in cancer survivors, with a focus on its pathophysiology.

\section{Characteristics of metabolic syndrome in cancer survivors}

Early studies of metabolic syndrome in cancer survivors focused on the tendency of children who had survived cancer treatment to be obese $\mathrm{e}^{10,11)}$, then, the patterns of glucose metabolism, insulin resistance, the changes in growth hormone
(GH) secretion, and the lipid profiles were analyzed. Survivors of childhood acute lymphoblastic leukemia (ALL) tend to have greater risk of obesity ${ }^{3,7,11)}$, glucose intolerance ${ }^{12)}$, lipid abnormalities ${ }^{9,13)}$, and cardiovascular events ${ }^{14)}$ compared to equivalently aged members of the general population. Table 1 summarizes the possible mechanisms underlying metabolic syndrome development that induced by different cancer treatments.

\section{Obesity}

Obesity is the main contributor to metabolic syndrome development. Excessive amounts of free fatty acids lead to insulin resistance and glucose intolerance, and the adipose

Table 1. Possible mechanisms underlying metabolic syndrome development that is induced by different cancer treatments

\begin{tabular}{|c|c|c|c|c|}
\hline Treatment & Specific treatment & Frequent diagnosis & Mechanism & Result \\
\hline \multirow[t]{6}{*}{ Surgery } & Brain surgery & Brain tumor & $\begin{array}{l}\text { Deficiency of hypothalamus-pituitary } \\
\text { axis hormones } \\
\text { Immobilization d/t neuro-muscular } \\
\text { defects }\end{array}$ & Metabolic syndrome \\
\hline & Removal of tumor & & & \\
\hline & Hydrocephalus & & & \\
\hline & $\begin{array}{l}\text { Intracranial hemorrhage } \mathrm{d} / \mathrm{t} \\
\text { tumor }\end{array}$ & & & \\
\hline & Orchiectomy & $\begin{array}{l}\text { Testicular cancer } \\
\text { Testicular involvement in } \\
\text { leukemia }\end{array}$ & Hypogonadism & Metabolic syndrome \\
\hline & Salpingo-oophrectomy & $\begin{array}{l}\text { Ovarian cancer } \\
\text { Other Germ cell tumor }\end{array}$ & Hypogonadism & Metabolic syndrome \\
\hline \multirow[t]{4}{*}{ Radiotherapy } & Cranial irradiation & $\begin{array}{l}\text { CNS involvement in leukemia } \\
\text { Brain tumor }\end{array}$ & $\begin{array}{l}\text { Deficiency of hypothalamus-pituitary } \\
\text { axis hormones }\end{array}$ & $\begin{array}{l}\text { Obesity, Dyslipidemia, } \\
\text { Insulin resistance }\end{array}$ \\
\hline & Radiation to thyroid region & $\begin{array}{l}\text { Head and neck cancer } \\
\text { (malignant lymphoma) }\end{array}$ & Hypothyroidism & Obesity, Dyslipidemia \\
\hline & Total body irradiation & Stem cell transplantation & $\begin{array}{l}\text { Multiple mechanism; direct damage to } \\
\text { endocrine organs } \\
\text { Or disturbance of hypothalamus- } \\
\text { pituitary axis }\end{array}$ & $\begin{array}{l}\text { Hypertension, } \\
\text { dyslipidemia, Insulin } \\
\text { resistance }\end{array}$ \\
\hline & Radiation to chest, abdomen & $\begin{array}{l}\text { Tumors in trunk or abdomen } \\
\text { (soft tissue sarcoma, } \\
\text { rhabdomyosarcoma, germ cell } \\
\text { tumor, neuroblastoma, etc.) }\end{array}$ & Direct damage to endocrine organs & $\begin{array}{l}\text { Hypertension, } \\
\text { dyslipidemia, Insulin } \\
\text { resistance }\end{array}$ \\
\hline \multirow[t]{5}{*}{ Chemotherapy } & Platinum (Cisplatin) & Various cancer & $\begin{array}{l}\text { Damage to vascular endothelium, } \\
\text { possibly damage mitochondria and } \\
\text { production of ROS }\end{array}$ & $\begin{array}{l}\text { Obesity, dyslipidemia, } \\
\text { metabolic syndrome }\end{array}$ \\
\hline & Alkylating agents & & & \\
\hline & Anthracyclines & & & \\
\hline & Camptothecins & & & \\
\hline & Antimetabolites & & Impaired lipid transport & Insulin resistance \\
\hline Hormonal therapy & $\begin{array}{l}\text { Androgen-deprivation } \\
\text { therapy }\end{array}$ & Testicular cancer & Hypogonadism & $\begin{array}{l}\text { Metabolic syndromes, } \\
\text { especially dyslipidemia, } \\
\text { insulin resistance }\end{array}$ \\
\hline \multirow[t]{2}{*}{ Other } & Muscle atrophy and inactivity & $\begin{array}{l}\text { All patients, especially } \\
\text { bed-ridden state }\end{array}$ & $\begin{array}{l}\text { Decreased insulin-stimulated glucose } \\
\text { uptake }\end{array}$ & $\begin{array}{l}\text { Insulin resistance, } \\
\text { obesity }\end{array}$ \\
\hline & $\begin{array}{l}\text { Dietary restriction and } \\
\text { antibiotics use }\end{array}$ & $\begin{array}{l}\text { All patients with } \\
\text { cancer treatment }\end{array}$ & $\begin{array}{l}\text { Disruption and damage to the intestinal } \\
\text { flora, reduced dietary uptake and } \\
\text { insulin secretion }\end{array}$ & Insulin resistance \\
\hline
\end{tabular}

CNS, central nervous system; ROS, reactive oxygen species. 
tissue is the main source of a variety of proinflammatory and prothrombotic cytokines that may contribute to the development of atherosclerotic cardiovascular changes ${ }^{2)}$.

The mechanism underlying the higher risk of obesity among cancer survivors is unclear. However, the findings from the St. Jude cohort studies indicate that childhood ALL survivors tend to have hypertension and higher fasting glucose and cholesterol levels, specifically, high triglyceride (TG) and low-density lipoprotein cholesterol (LDL-C) levels ${ }^{14)}$. Moreover, almost half of the survivors had body mass indices (BMIs) that were over 30 $\mathrm{kg} / \mathrm{m}^{2}$. Risk analyses have shown that being male and Caucasian, and prior cranial irradiation with or without craniospinal irradiation are important risk factors associated with metabolic syndrome ${ }^{5,14)}$. More recently, radiation- or chemotherapeutic agent-induced GH deficiency (GHD) has been determined to be the most important cause of obesity in cancer survivors ${ }^{15}$.

\section{Dyslipidemia}

Dyslipidemic features, including hypertriglyceridemia, high LDL-C levels, and low high-density lipoprotein cholesterol (HDL-C) levels, have been described in cancer survivors ${ }^{13,16,17)}$. The findings from many well-controlled and well-designed studies with few variables have demonstrated that cancer survivors are more dyslipidemic than control population. Since this cannot be explained by distinct factors, the genetic risk factors for obesity and dyslipidemia among adult childhood cancer survivors has been evaluated.

The features of dyslipidemia are closely related to cardiovascular risk. If the treatment modalities patient received are cardiotoxic, for example, anthracyclines, chest radiation, and hematopoietic stem cell transplantation, the patient will have a greater risk of cardiovascular events ${ }^{14,18}$. Hence, our attention should focus on the timing of care initiation for childhood cancer survivors.

\section{Genetic factors}

Ross et al. ${ }^{19)}$ reported that leptin receptor gene polymorphisms may influence obesity in female childhood ALL survivors, particularly those who had undergone cranial irradiation. Wilson et al. ${ }^{20)}$ reported the results from a genomewide association analysis of patients who had survived ALL treatment, and found several single nucleotide polymorphisms associated with obesity and cranial irradiation. Other attempts to find genetic differences among childhood leukemia survivors are ongoing ${ }^{5,17,21)}$.

\section{Pathophysiology related to anticancer treatment}

\section{Surgery}

Surgery can induce endocrine deficiencies by directly damaging the endocrine organs. Removing brain tumors can damage the hypothalamic-pituitary axis, which causes several hormonal and metabolic changes, and, eventually, metabolic syndrome. Orchiectomies, thyroidectomies, and oophorectomies induce sex hormone deficiencies, and the replacement of these hormones is an important factor associated with metabolic syndrome development ${ }^{22)}$.

\section{Radiotherapy}

Radiotherapy causes direct organ damage in a dose-dependent manner. Resistance to radiation differs according to the organ undergoing treatment. Regarding the brain, isolated GHD can be induced by doses of 18-24 Gy, which are frequently used for cranial irradiation in patients with ALL with central nervous system involvement ${ }^{23)}$. Doses of 30-50 Gy, which are usually used in patients with average-risk brain tumors, can permanently damage the gonadotropin, adrenocorticotropin, and thyrotropin axes, and doses that are higher than $60 \mathrm{~Gy}$, that is, "full-dose radiation," cause panhypopituitarism ${ }^{23)}$, and these radiation doses damage other neurocognitive functions, thereby preventing patients from having ordinary "healthy" lifestyles. Patients who undergo hematopoietic stem cell transplantations with total body irradiation (TBI) as a conditioning regimen have higher diabetes and cardiovascular risks ${ }^{18)}$.

\section{Chemotherapy}

While the exact role that chemotherapy plays in contributing to metabolic syndrome is unclear, chemotherapy is thought to induce metabolic syndrome, in part, by inducing gonadal hormone deficiencies ${ }^{2)}$. Alkylating agents, anthracyclines, camptothecins, epipodophyllotoxins, and platinum-based agents are frequently used to treat pediatric cancers, and they disrupt DNA replication and transcription, and protein synthesis, thereby interrupting cell regeneration and growth. Endocrine cells might be more sensitive to the injury caused by these agents than other cells $s^{4}$. Moreover, these agents might interact with receptors or secondary messengers, thereby disrupting the hormonal axes ${ }^{4}$.

Chemotherapeutic agents induce insulin resistance, hyperinsulinemia, and impaired glucose control by directly influencing insulin sensitivity ${ }^{24)}$. Alkylating agents, anthracyclines, camptothecins, epipodophyllotoxins, and platinum-based agents produce reactive oxygen species that mediate the anticancer effects, which lead to mitochondrial dysfunction ${ }^{15)}$. Anemia, apoptosis, and cell lysis may lead to tissue hypoxia that causes the release of proinflammatory cytokines and macrophage activation ${ }^{15}$. All of these effects could contribute to the development of obesity, insulin resistance, and dyslipidemia, and, ultimately, metabolic syndrome.

\section{Hormone therapy}

The hormone-modifying therapeutic agents used in prostate 
cancer and breast cancer are associated with an increased risk of metabolic syndrome ${ }^{22,24)}$. These agents increase the LDL-C and TG levels, and insulin resistance, which leads to poor glycemic control in a prediabetic state. The cardiovascular and thromboembolism risks also increase following treatment with these agents ${ }^{25,26}$. Fortunately, these agents are rarely used to treat pediatric cancer. However, risk of hormone or similar agents should be aware of for many clinicians caring cancer survivors.

\section{Hormonal changes after anticancer treatment}

Injuries to the hypothalamic-pituitary axis may cause somatotropin, thyrotropin, gonadotropin, and adrenocorticotropin imbalances, thereby causing specific hormonal deficiencies. Hormonal problems, especially those involving $\mathrm{GH}$, thyroid hormones, and sex hormones are associated with metabolic syndrome ${ }^{2)}$. While cranial radiotherapy clearly disrupts the hypothalamic-pituitary axis dose dependently ${ }^{23)}$, the effects of chemotherapy on the hypothalamus and pituitary gland require further investigation.

\section{Growth hormone deficiency}

The impact of GHD on the height of childhood cancer survivors is well established. In addition to stimulating growth, $\mathrm{GH}$ stimulates protein synthesis, contributes to lipolysis, and it indirectly exerts insulin-like effects that include stimulating the uptake of glucose by the peripheral tissues by stimulating insulin-like growth factor-1 production by the liver and local tissues. Thus, GHD changes the body's composition by, for example, increasing the fat mass and causing obesity, which are associated with dyslipidemia and insulin resistance ${ }^{6,7)}$.

Cranial radiotherapy is a major risk factor for obesity, dyslipidemia, and insulin resistance in childhood cancer survivors ${ }^{5,17)}$. Hence, cranial radiotherapy may induce GHD, which may cause metabolic syndrome development. Since cranial radiotherapy used less frequently to treat childhood ALL and other cancers nowadays, the incidence of secondary GHD might decline. However, GHD has been reported in patients who did not undergo cranial radiotherapy ${ }^{5)}$, which suggests that chemotherapy can also damage the hypothalamic-pituitary axis, but the mechanism underlying this damage is unknown.

\section{Thyroid hormone deficiencies}

The thyroid hormones are important for regulating the metabolism, and hypothyroidism and even a low-level euthyroid state are closely associated with metabolic syndrome that manifests as an increased waist circumference, increased TG and fasting glucose levels, and decreased HDL-C levels ${ }^{27)}$.

Hypothyroidism is frequently seen after radiotherapy around the thyroid gland. The 5-year risk for hypothyroidism varies from $20 \%$ to $48 \%$ in patients with head and neck cancer who undergo radiotherapy ${ }^{28)}$. Cranial irradiation and TBI associated with hematopoietic stem cell transplantations can cause primary and secondary hypothyroidism ${ }^{29}$. However, the findings from some studies demonstrate that patients who receive chemotherapy only show a high prevalence of subclinical hypothyroidism $^{2,30)}$. Therefore, knowledge about chemotherapyinduced hypothyroidism remains limited.

\section{Gonadotropin and sex hormone deficiencies}

Low testosterone levels are associated with visceral obesity, insulin resistance, and dyslipidemia, and, therefore, an increased risk of metabolic syndrome development ${ }^{2}$. Estrogen deficiencies are associated with central obesity, dyslipidemia, and insulin resistance ${ }^{24)}$. Testosterone deficiencies in cancer survivors can be caused by orchiectomy and by direct damage from radiotherapy or chemotherapy with alkylating agents and heavy metals. Estrogen deficiencies in cancer survivors are usually caused by oophorectomy and by direct damage from radiotherapy or chemotherapy. One study's findings showed that low estrogen levels induced by bilateral oophorectomies were associated with an increased prevalence of metabolic syndrome ${ }^{31)}$. In addition, effects of radiotherapy or gonadotropin-releasing hormone agonists used as anticancer treatment on the hypothalamicpituitary axis might cause secondary gonadal dysfunction. Cranial radiotherapy for brain tumors or ALL is associated with secondary gonadal dysfunction in childhood cancer survivors ${ }^{31)}$.

\section{Changes in energy metabolism after anticancer treatment}

Mayer et al. ${ }^{32)}$ showed reduced levels of energy expenditure in childhood ALL survivors treated with cranial radiotherapy, which were thought to be caused by damage to the hypothalamic-pituitary axis and the development of GH and thyroid hormone deficiencies. This damage might also induce hypothalamic resistance to leptin's negative feedback effect on energy intakes and its positive feedback effect on energy expenditure. Therefore, childhood ALL survivors could be at an increased risk of becoming obese ${ }^{33}$. Cancer survivors who underwent hematopoietic stem cell transplantations showed similar manifestations $^{31)}$.

The mechanisms by which cancer treatments other than radiotherapy induce metabolic syndrome are unclear. Direct toxicity could lead to dysfunctional adipose tissues in cancer survivors, thereby contributing to body composition changes, insulin resistance, and the increased production of proinflammatory adipokines.

\section{Other sequelae of anticancer treatment}

Treatment-related neurotoxicity might induce autonomic dysfunction. Impairment of the arterial baroreflex is associated with an increase in sympathetic nervous activity and metabolic syndrome development ${ }^{2}$. Furthermore, specific complications 
caused by surgery or other anticancer treatments might make patients physically disabled. Patients with osteosarcomas, Ewing sarcomas, and brain tumors have noticeably reduced physical performance levels compared with patients with other cancers ${ }^{34)}$. These complications can limit a patient's physical activity levels, thereby increasing the risk of metabolic syndrome.

\section{Cancer survivors' lifestyle factors}

Lifestyle factors, including exercise, diet, consuming alcohol, and smoking, affect the risk of developing metabolic syndrome. Cancer-treatment-related lifestyle changes caused by somatic complications or psychological factors, including stress and health consciousness, are important factors associated with the quality of life. Childhood cancer survivors are less physically active than their siblings, and physical, neurocognitive, and cardiorespiratory restrictions are important contributing factors $^{34)}$.

\section{Studies into intervention and prevention}

Cancer survival comprises follow-up assessments to detect relapses, counsel patients to maintain good health, and manage complications associated with cancer treatments. Pediatric oncologists and endocrinologists who manage cancer survivors should be aware of the potential effects of cancer treatment, including its delayed cardiometabolic effects and metabolic syndrome. While strategies have been established to manage metabolic syndrome in the general population, applying these guidelines to cancer survivors remains controversial.

\section{Lifestyle modifications}

Treating metabolic syndrome consists of lifestyle interventions with or without drug therapy ${ }^{35)}$. Smoking cessation, lowering cholesterol levels, especially the LDL-C and TG levels, dietary interventions, exercise, and blood pressure management are the primary targets. Lifestyle interventions are initially recommended for metabolic syndrome, but if these are inadequate, drug therapies for the abnormalities associated with the individual risk factors may be indicated. According to the current guidelines, cardiovascular risk estimates and decisions about initiating drug treatment are largely based on age, and only 10 -year risks are predicted ${ }^{24)}$. However, childhood cancer survivors tend to be young when problems arise; hence, the guidelines are insufficient for younger cancer survivors ${ }^{36)}$.

\section{Exercise intervention}

Although data describing the long-term effects of lifestyle interventions on cancer survivors are scarce, the findings from a recent short-term study of lifestyle interventions that mainly comprised exercise are promising. Bao et al. ${ }^{37)}$ evaluated the impact of exercise in a population-based prospective cohort study of 1,696 breast cancer survivors and showed that exercise was inversely associated with the prevalence of metabolic syndrome, and that regular exercise participation reduced its prevalence. Similarly, Grote et al. ${ }^{38)}$ studied the effects of exercise on patients who had survived different types of cancer, and their findings showed that a 3 day/week, 13-week exercise intervention improved the cardiometabolic health of cancer survivors. These investigators noted that the intervention was less effective in non-Caucasian survivors compared with Caucasian survivors, which warrants undertaking larger, multiethnic studies. However, no study reports describe the effects of lifestyle modifications on childhood cancer survivors.

\section{Dietary and nutritional interventions}

Cancer patients have poor health statuses, because of cachexia that develops during treatment and immobilization. However, few studies have focused on cancer survivors' nutrition and their health posttreatment. Tonorezos et al. ${ }^{39)}$ analyzed the relationship between nutrition and metabolic syndrome in 117 adult survivors of childhood ALL, and showed that those who ate a Mediterranean diet had a lower prevalence of metabolic syndrome. Smith et al. ${ }^{40)}$ reported that adhering to the so-called "good lifestyle and nutrition" habits recommended by the World Cancer Research Fund/American Institute for Cancer Research (WCRF/AICR) guidelines was associated with a low risk of metabolic syndrome in the St. Jude Lifetime cohort. The WCRF/ AICR guidelines recommend maintaining a BMI below $25 \mathrm{~kg} /$ $\mathrm{m} 2$, daily physical activity, daily fruit and vegetable intakes of over five servings/day, daily complex carbohydrate intakes of over $400 \mathrm{~g} /$ day, reducing daily alcohol intakes to below $14 \mathrm{~g} /$ day for women and $28 \mathrm{~g} /$ day for men, reducing daily red meat intakes to below $80 \mathrm{~g} /$ day, and reducing sodium intakes to below $2.4 \mathrm{~g} /$ day. However, $87.8 \%$ of the men and $87.2 \%$ of the women in the St. Jude Lifetime cohort did not follow the WCRF/AICR guidelines, and nearly $40 \%$ of the men and women showed the characteristics associated with metabolic syndrome.

A recent Cochrane review analyzed three randomized controlled studies of cancer survivors' nutrition ${ }^{41)}$. Two studies' findings showed that interventions comprising calcium and vitamin D intakes did not influence bone cancer survivors' bone mineral densities. The third study's findings showed that cancer survivors tend to eat more junk food than the general population. The Cochrane review concluded that these studies failed to demonstrate the effects of nutritional interventions and that to elucidate the role of nutritional interventions on metabolic syndrome; further well-designed controlled studies are needed.

To date, no randomized controlled studies have been undertaken to investigate the impact of nutritional interventions on metabolic syndrome in childhood cancer survivors. Nevertheless, it seems reasonable to advise patients to follow the lifestyle and nutrition recommendations to reduce metabolic 
syndrome and cardiovascular event risks.

\section{Optimal timing of interventions and education}

The timing of lifestyle interventions is important. Lifestyle interventions usually begin after cancer treatment is completed. Nevertheless, whether there is a difference between exercising during or after cancer treatment and the extent of any difference remain unknown.

Weight gains start during therapy and obesity persists at the end of treatment, irrespective of whether patients undergo cranial radiotherapy ${ }^{5}$, which suggests that the risk of developing metabolic syndrome starts to increase during cancer treatment. Thus, initiating lifestyle modifications as early as possible, that is, during cancer treatment, would, theoretically, be more helpful at preventing weight gains and reducing the cardiovascular risk. If a patient exercises during cancer treatment, they can maintain a healthy weight and body composition, and prevent metabolic syndrome development. In addition, by including these lifestyle modifications during cancer treatment, these changes will be incorporated into the rest of the patients' lives, thereby helping to improve the quality of life ${ }^{24)}$.

However, exercising during cancer treatment might be impossible for some patients, because of their clinical courses, cancer treatment intensities, and the severities of the cancers themselves. Hence, the timing and modes of lifestyle modifications and interventions should be customized to each patient's needs. Health care providers should prepare effective exercise and dietary intervention programs. Education and emphasizing the importance of lifestyle modifications should begin at the time of the cancer diagnosis and treatment.

\section{Medical treatment}

The current metabolic syndrome management guidelines recommend appropriate pharmaceutical management if lifestyle modifications do not improve the manifestations of metabolic syndrome ${ }^{35)}$. The guideline parameters for drug therapy for dyslipidemia, hypertension, and elevated plasma glucose levels are based on specific coronary heart disease risk categories in adults that are derived from large, long-term observational studies, and no randomized controlled or longterm cohort studies of cancer survivors have been undertaken. Cancer survivors should be considered to have a specific cardiovascular risk that is posed by cancer treatment; therefore, their pharmaceutical management should be tailored to their individual needs.

Replacing GH might be possible for cancer survivors with GHD. Follin et al. ${ }^{42)}$ reported that young adult childhood ALL survivors with GHD showed significant decreases in their serum leptin levels, leptin levels per kg fat mass, plasma glucose levels, and their waist and hip circumferences after 12 months of GH replacement therapy. However, no randomized studies of GH replacement therapy in childhood cancer survivors have been undertaken. The results from the Genetics and Neuroendocrinology of Short Stature International Study and the Hypopituitary Control and Complications Study ${ }^{43)}$ demonstrated that secondary neoplasms in childhood cancer survivors administered $\mathrm{GH}$ replacement therapy occurred in $3.8 \%$ of children and in $6.0 \%$ of adults, and that the estimated cumulative frequencies of secondary neoplasms after 5 years were $6.2 \%$ and $4.8 \%$, respectively. Further studies are needed to determine the efficacy and safety of GH replacement therapy in childhood cancer survivors who have GHDs induced by cancer treatments.

\section{Conclusions}

Childhood cancer survivors experience many problems after cancer treatment, but one of the most important complications is metabolic syndrome. Much remains to be discovered about the pathophysiology underlying metabolic syndrome in cancer survivors, including the genetic and environmental factors. Clearly, the cardiovascular risk caused by metabolic syndrome in cancer survivors is considerably higher than that in the general population. Childhood cancer survivors will increase in number as overall survival improves. Hence, to manage these children and adults effectively, the coordinated efforts of oncologists, endocrinologists, rehabilitation physicians, and other health care providers are required. This review may guide the next steps for further studies, and provide insights that help to evaluate and effectively manage high-risk childhood cancer survivors.

\section{Conflict of interest}

No potential conflict of interest relevant to this article was reported.

\section{References}

1. Park HJ, Moon EK, Yoon JY, Oh CM, Jung KW, Park BK, et al. Incidence and survival of childhood cancer in Korea. Cancer Res Treat 2016;48:869-82.

2. de Haas EC, Oosting SF, Lefrandt JD, Wolffenbuttel BH, Sleijfer DT, Gietema JA. The metabolic syndrome in cancer survivors. Lancet Oncol 2010;11:193-203.

3. Talvensaari KK, Lanning M, Tapanainen P, Knip M. Longterm survivors of childhood cancer have an increased risk of manifesting the metabolic syndrome. J Clin Endocrinol Metab 1996;81:3051-5.

4. Casco S, Soto-Vega E. Development of metabolic syndrome associated to cancer therapy: review. Horm Cancer 2016;7:289-95.

5. Gibson TM, Ehrhardt MJ, Ness KK. Obesity and metabolic syndrome among adult survivors of childhood leukemia. Curr Treat Options Oncol 2016;17:17.

6. Lim HH, Kang MJ, Yun IS, Lee YA, Shin CH, Yang SW. 
Prevalence and risk factors of the metabolic syndrome in young adults with childhood-onset hypopituitary growth hormone deficiency. Korean J Pediatr 2010;53:892-7.

7. Sohn YB, Kim SJ, Park SW, Kim SH, Cho SY, Lee SH, et al. The metabolic syndrome and body composition in childhood cancer survivors. Korean J Pediatr 2011;54:2539.

8. Bang KW, Seo SY, Lee JW, Jang PS, Jung MH, Chung NG, et al. Evaluation of changes in random blood glucose and body mass index during and after completion of chemotherapy in children with acute lymphoblastic leukemia. Korean J Pediatr 2012;55:121-7.

9. Shin H, Choi YJ, Lee YH, Shin JH, Yang S. Prevalence of the components of metabolic syndrome in childhood cancer survivors. Clin Pediatr Hematol Oncol 2014;21:23-8.

10. Odame I, Reilly JJ, Gibson BE, Donaldson MD. Patterns of obesity in boys and girls after treatment for acute lymphoblastic leukaemia. Arch Dis Child 1994;71:147-9.

11. Didi M, Didcock E, Davies HA, Ogilvy-Stuart AL, Wales JK, Shalet SM. High incidence of obesity in young adults after treatment of acute lymphoblastic leukemia in childhood. J Pediatr 1995;127:63-7.

12. Neville KA, Cohn RJ, Steinbeck KS, Johnston K, Walker JL. Hyperinsulinemia, impaired glucose tolerance, and diabetes mellitus in survivors of childhood cancer: prevalence and risk factors. J Clin Endocrinol Metab 2006;91:4401-7.

13. Malhotra J, Tonorezos ES, Rozenberg M, Vega GL, Sklar CA, Chou J, et al. Atherogenic low density lipoprotein phenotype in long-term survivors of childhood acute lymphoblastic leukemia. J Lipid Res 2012;53:2747-54.

14. Nottage KA, Ness KK, Li C, Srivastava D, Robison LL, Hudson MM. Metabolic syndrome and cardiovascular risk among long-term survivors of acute lymphoblastic leukaemia - From the St. Jude Lifetime Cohort. Br J Haematol 2014;165:364-74.

15. Rosen GP, Nguyen HT, Shaibi GQ. Metabolic syndrome in pediatric cancer survivors: a mechanistic review. Pediatr Blood Cancer 2013;60:1922-8.

16. Barbosa-Cortés L, López-Alarcón M, Mejía-Aranguré JM, Klünder-Klünder M, Del Carmen Rodríguez-Zepeda M, Rivera-Márquez H, et al. Adipokines, insulin resistance, and adiposity as a predictors of metabolic syndrome in child survivors of lymphoma and acute lymphoblastic leukemia of a developing country. BMC Cancer 2017;17:125.

17. Morel S, Leahy J, Fournier M, Lamarche B, Garofalo C, Grimard G, et al. Lipid and lipoprotein abnormalities in acute lymphoblastic leukemia survivors. J Lipid Res 2017;58:982-93.

18. Armenian SH, Sun CL, Vase T, Ness KK, Blum E, Francisco $\mathrm{L}$, et al. Cardiovascular risk factors in hematopoietic cell transplantation survivors: role in development of subsequent cardiovascular disease. Blood 2012;120:450512.

19. Ross JA, Oeffinger KC, Davies SM, Mertens AC, Langer EK, Kiffmeyer WR, et al. Genetic variation in the leptin receptor gene and obesity in survivors of childhood acute lymphoblastic leukemia: a report from the Childhood Cancer Survivor Study. J Clin Oncol 2004;22:3558-62.

20. Wilson CL, Liu W, Yang JJ, Kang G, Ojha RP, Neale GA, et al. Genetic and clinical factors associated with obesity among adult survivors of childhood cancer: a report from the St. Jude Lifetime Cohort. Cancer 2015;121:2262-70.

21. Marcoux S, Drouin S, Laverdière C, Alos N, Andelfinger GU, Bertout L, et al. The PETALE study: Late adverse effects and biomarkers in childhood acute lymphoblastic leukemia survivors. Pediatr Blood Cancer 2017;64.

22. Kate A, Kadambari D. Incidence of metabolic syndrome in breast cancer survivors on adjuvant hormonal therapy. J Pharmacol Pharmacother 2016;7:28-30.

23. Darzy KH, Shalet SM. Hypopituitarism following radiotherapy. Pituitary 2009;12:40-50.

24. Westerink NL, Nuver J, Lefrandt JD, Vrieling AH, Gietema JA, Walenkamp AM. Cancer treatment induced metabolic syndrome: Improving outcome with lifestyle. Crit Rev Oncol Hematol 2016;108:128-36.

25. Meinardi MT, Gietema JA, van der Graaf WT, van Veldhuisen DJ, Runne MA, Sluiter WJ, et al. Cardiovascular morbidity in long-term survivors of metastatic testicular cancer. J Clin Oncol 2000;18:1725-32.

26. Sheean P, Liang H, Schiffer L, Arroyo C, Stolley M. Examining the prevalence of metabolic syndrome among overweight/obese African-American breast cancer survivors vs. matched non-cancer controls. J Cancer Surviv 2017;11:102-10.

27. Roos A, Bakker SJ, Links TP, Gans RO, Wolffenbuttel $\mathrm{BH}$. Thyroid function is associated with components of the metabolic syndrome in euthyroid subjects. J Clin Endocrinol Metab 2007;92:491-6.

28. Tell R, Lundell G, Nilsson B, Sjödin H, Lewin F, Lewensohn R. Long-term incidence of hypothyroidism after radiotherapy in patients with head-and-neck cancer. Int J Radiat Oncol Biol Phys 2004;60:395-400.

29. Sanders JE, Hoffmeister PA, Woolfrey AE, Carpenter PA, Storer BE, Storb RF, et al. Thyroid function following hematopoietic cell transplantation in children: 30 years' experience. Blood 2009;113:306-8.

30. Mohapatra S, Bansal D, Bhalla AK, Verma Attri S, Sachdeva $\mathrm{N}$, Trehan A, et al. Is there an increased risk of metabolic syndrome among childhood acute lymphoblastic leukemia survivors? A developing country experience. Pediatr Hematol Oncol 2016;33:136-49.

31. Green DM, Sklar CA, Boice JD Jr, Mulvihill JJ, Whitton JA, Stovall M, et al. Ovarian failure and reproductive outcomes after childhood cancer treatment: results from the Childhood Cancer Survivor Study. J Clin Oncol 2009;27:2374-81.

32. Mayer EI, Reuter M, Dopfer RE, Ranke MB. Energy expenditure, energy intake and prevalence of obesity after therapy for acute lymphoblastic leukemia during childhood. Horm Res 2000;53:193-9.

33. Brennan BM, Rahim A, Blum WF, Adams JA, Eden OB, Shalet SM. Hyperleptinaemia in young adults following 
cranial irradiation in childhood: growth hormone deficiency or leptin insensitivity? Clin Endocrinol (Oxf) 1999;50:163-9.

34. Ness KK, Hudson MM, Ginsberg JP, Nagarajan R, Kaste SC, Marina N, et al. Physical performance limitations in the Childhood Cancer Survivor Study cohort. J Clin Oncol 2009;27:2382-9.

35. Grundy SM, Cleeman JI, Daniels SR, Donato KA, Eckel $\mathrm{RH}$, Franklin BA, et al. Diagnosis and management of the metabolic syndrome: an American Heart Association/ National Heart, Lung, and Blood Institute Scientific Statement. Circulation 2005;112:2735-52.

36. Rugbjerg K, Mellemkjaer L, Boice JD, Køber L, Ewertz M, Olsen JH. Cardiovascular disease in survivors of adolescent and young adult cancer: a Danish cohort study, 1943-2009. J Natl Cancer Inst 2014;106:dju 110.

37. Bao PP, Zheng Y, Nechuta S, Gu K, Cai H, Peng P, et al. Exercise after diagnosis and metabolic syndrome among breast cancer survivors: a report from the Shanghai Breast Cancer Survival Study. Cancer Causes Control 2013;24:1747-56.

38. Grote S, Almstedt HC, Tarleton HP. Cardiometabolic Health Among Cancer Survivors: A 13-week pilot study of a combined aerobic and resistance training program. Oncol
Nurs Forum 2016;43:306-15.

39. Tonorezos ES, Robien K, Eshelman-Kent D, Moskowitz CS, Church TS, Ross R, et al. Contribution of diet and physical activity to metabolic parameters among survivors of childhood leukemia. Cancer Causes Control 2013;24:31321.

40. Smith WA, Li C, Nottage KA, Mulrooney DA, Armstrong GT, Lanctot JQ, et al. Lifestyle and metabolic syndrome in adult survivors of childhood cancer: a report from the St. Jude Lifetime Cohort Study. Cancer 2014;120:2742-50.

41. Cohen JE, Wakefield CE, Cohn RJ. Nutritional interventions for survivors of childhood cancer. Cochrane Database Syst Rev 2016;(8):CD009678.

42. Follin C, Thilén U, Ahrén B, Erfurth EM. Improvement in cardiac systolic function and reduced prevalence of metabolic syndrome after two years of growth hormone $(\mathrm{GH})$ treatment in GH-deficient adult survivors of childhood-onset acute lymphoblastic leukemia. J Clin Endocrinol Metab 2006;91:1872-5.

43. Woodmansee WW, Zimmermann AG, Child CJ, Rong Q, Erfurth EM, Beck-Peccoz P, et al. Incidence of second neoplasm in childhood cancer survivors treated with GH: an analysis of GeNeSIS and HypoCCS. Eur J Endocrinol 2013;168:565-73. 